\title{
ĐẶC ĐIỂM CÁC DẤU ẤN HBV Ở BÊ̂NH NHÂN NHIỄM HBV MẮC U LYMPHO TAI TRUNG TÂM HUYẾT HOC VÀ TRUYỀN MÁU BÊ̂NH VIỆN BACCH MAI
}

\author{
Lê Thị Huyền ${ }^{1}$, Nguyễn Tuấn Tùng ${ }^{2}$, Nguyễn Vũ Hồng Vân ${ }^{1}$, \\ Trương Thái Phương ${ }^{3}$, Lê Trung Dũng ${ }^{3}$, Tống Văn Giáp ${ }^{2}$, \\ Nguyễn Thị Thùy Dương ${ }^{2}$, Phạm Thị Huế ${ }^{2}$, Nguyễn Văn Dũng
}

\section{TÓM TẮT}

Mục tiêu: Mô tả các dấu ấn HBV (Hepatitis B Virus) của bệnh nhân nhiếm HBV mắc u lympho. Phương pháp nghiên cứu: Nghiên cứu mô tả cắt ngang 25 bệnh nhân nhiếm HBV mắc u lympho điêu trị tai Trung tâm Huyết học và Truyền máu - Bệnh viện Bạch Mai từ tháng 8/2020 đến tháng 7/2021 Kết quả: $23 / 25$ bênh nhẩn mắc u lympho non-Hodgkin

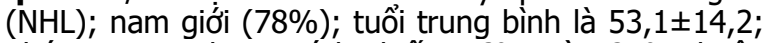
nhóm $\mathrm{HBsAg}$ dương tính chiếm $76 \%$, còn $24 \%$ thuốc nhóm HBsAg âm tính và anti-HBc total dương tính. $\mathrm{HBeAg}$ và anti-HBe dương tính ở $23,5 \%$ và $35,3 \%$ bệnh nhân được xét nghiệm tương ứng. Tỷ lệ phát hiện HBV-DNA $85 \%$ bất kể tình trạng HBsAg trong những bệnh nhân được xét nghiệm, với giá trị thấp nhất là 1,69 $\log \mathrm{IU} / \mathrm{ml}$, cao nhất là $8,59 \log \mathrm{IU} / \mathrm{ml}$, trung bình là 4,38 $\log I U / m l$. Chúng tôi ghi nhận 1 trường hợp HBsAg âm tính, anti-HBs dương tính và phát hiện HBV-DNA trong huyết thanh. Kết luận: Trong nghiển cứu của chúng tôi, bệnh nhân có HBssag dương tính chiếm tỷ lệ cao hơn so với bệnh nhân có HBsAg âm tính, anti-HBc total dương tính mắc u lympho. Việc tâm soát ban đâuu nên được thực hiện đây đủ các xét nghiệm để tránh bỏ sót nhóm đối tượng cần được dự phòng.

Tư khóa: Vi rút viêm gan $B$, u lympho Hodgkin, u lympho Non-Hodgkin.

\section{SUMMARY}

CHARACTERISTICS OF HBV MARKERS IN HBV-INFECTED PATIENTS WITH LYMPHOMA AT HEMATOLOGY AND BLOOD TRANSFUSION CENTER OF BACH MAI HOSPITAL

Objectives: Describe HBV (Hepatitis B Virus) markers of HBV-infected patients with lymphoma. Methods: A Cross-sectional descriptive study of 25 HBV-infected patients with lymphoma treated at Hematology and Blood Transfusion Center - Bach Mai Hospital. Results: 23/25 patients were diagnosed with non-Hodgkin lymphoma; male (78\%); mean age

\footnotetext{
${ }^{1}$ Truyền nhiễm và các Bệnh Nhiệt đới trường Đại học Y Hà Nội,

${ }^{2} T$ t Huyết học và truyền máu, Bệnh viện Bạch Mai

${ }^{3}$ Bệnh viện Bạch Mai,

${ }^{4}$ Trung tâm Bệnh Nhiệt đới, Bệnh viện Bạch Mai

Chịu trách nhiệm chính: Lê Thị Huyền

Email: huyenlongly95@gmail.com

Ngày nhận bài: 26.7.2021

Ngày phản biên khoa họ: 29.9.2021

Ngày duyệt bài: 5.10 .2021
}

was $53,1 \pm 14,2$. Patients with $\mathrm{HBsAg}$ positive accounted for $76 \%$, $24 \%$ remaining were belonged to the $\mathrm{HBsAg}$ negative and anti-HBc total positive. $\mathrm{HBeAg}$ and anti-HBe were positive in $23,5 \%$ and $35,3 \%$ of tested patients, respectively. HBV-DNA was detected in $85 \%$ regardless of HBsAg status in tested patients, with the lowest level was $1,69 \mathrm{log} I U / \mathrm{ml}$, the highest was $8,59 \log I U / m l$, and the mean was $4,38 \log I U / \mathrm{ml}$. We recorded 1 case with HBsAg negative, anti-HBs positive and HBV-DNA's serum was detected. Conclusion: In our study, the proportion of $\mathrm{HBsAg}$ positive patients was higher than that of HBsAgnegative, anti-HBc total positive patients with lymphoma. A full test for the first screening was required before lymphoma's treatment to avoid missing patients who need to be prevented.

Keywords: Hepatitis B virus, Hodgkin lymphoma, Non-Hodgkin lymphoma.

\section{I. ĐĂT VẤN ĐỀ}

Nhiễm vi rút viêm gan $B$ (Hepatitis $B$ virus: HBV) hiện vẫn là mối đe dọa sức khỏe toàn câu. Hiệp hội nghiên cưu bệnh gan châu Âu (European Association for the Study of the Liver: EASL) năm 2017 ước tính toàn câu có khoảng 240 triệu người nhiễm HBV mạn, với tỷ lệ người có HBsAg (Hepatitis B surface Antigen: HBsAg) dương tính dao động từ thấp $(<2 \%)$ đến cao $(>8 \%)^{1}$. Sự ra đời của các thuốc uống nucleot(s) ide analogues (NAs) đã mở ra một kỷ nguyên mới trong điều trị ở những bệnh nhân nhiễm HBV. Tuy vậy, các loại thuốc điều trị viêm gan B hiện nay đều không thể loại bỏ hoàn toàn HBV. Chính sự tồn tại của DNA vòng đóng hóa trị (Covalently closed circular DNA: cccDNA) và HBV-DNA tích hợp vào ADN làm cho những bệnh nhân nhiễm HBV mạn luôn tiềm ẩn nguy cơ tái hoạt động vi rút, đặc biệt là khi bệnh nhân có trang thái miễn dịch bi ức chế như điều trị hóa chất, đặc biệt là các phác đồ có chứa kháng thể đơn dòng chống lại protein CD20 như rituximab, hay gặp ở những bệnh nhân điêuu trị u lympho bao gồm u lympho Hodgkin (Hodgkin lymphoma: $\mathrm{HL}$ ) và u lympho non-Hodgkin (non-Hodgkin lymphoma: $\mathrm{NHL}$ ). Biểu hiện lâm sàng của tái hoạt HBV có thể khác nhau từ không triệu chứng và tự giới hạn đến suy gan cấp tính và thậm chí tử vong. Kết quả cuối cùng của điều trị bệnh u 
lympho bị ảnh hưởng đáng kể ở những bệnh nhân có nhiễm HBV, không chỉ tăng tỷ lệ tử vong, mà cả tỷ lệ sống thêm toàn bộ (Overal Survival: OS) và thời gian sống bệnh nhân không tiến triển (Progression-Free survival: PFS) dường như đều kém hơn so với nhóm không nhiễm $\mathrm{HBV}^{2}$. Tuy nhiên, nguy cơ tái hoạt động HBV có thể dự phòng hiệu quả bằng sàng lọc đầy đủ và sử dụng NAs. Với mong muốn đem lại cái nhìn tổng quan về đặc điểm của các bệnh nhân nhiễm vi rút viêm gan $\mathrm{B}$ mắc u lympho, chúng tôi tiến hành nghiên cứu "Đặc điểm các dấu ấn HBV ở bệnh nhân nhiễm HBV mắc u lympho điều trị tại trung tâm Huyết học và Truyền máu Bệnh viện Bach Mai".

\section{II. ĐỐI TƯỚNG VÀ PHƯƠ'NG PHÁP NGHIÊN CỨU}

2.1. Đối tượng nghiên cứu: Gồm 25 bệnh nhân nhiễm HBV mắc u lympho điều trị tại Trung tâm Huyết học và Truyền máu - Bệnh viện Bạch Mai từ tháng 8/2020 đến tháng $7 / 2021$

\subsection{Phương pháp nghiên cứu}

2.2.1. Phương pháp nghiên cứu. Mô tả cắt ngang 2.2.2. Tiêu chuân lựa chọn

- Bệnh nhân nhiễm HBV: HBsAg dương tính hoặc HBsAg âm tính và anti-HBc total (total Hepatitis B core antibody) dương tính

- Bệnh nhân mắc u lympho: Bao gồm bệnh nhân mắc u lympho Hodgkin và u lympho NonHodgkin, chẩn đoán dựa trên hướng dẫn chẩn đoán và điều trị một số bệnh lý huyết học của Bộ Y tế năm 2015.

- Bệnh nhân từ 18 tuổi trở lên.

2.2.3. Tiêu chuẩn loại trừ

- Bệnh nhân đồng nhiễm với vi rút viêm gan C

- Bệnh nhân đồng nhiễm HIV

2.2.4. Các chỉ tiêu nghiên cứu

- Các bênh nhân được đánh giá về tuổi, giới tính, tiền sử phát hiện và điều trị viêm gan vi rút $B$, tiên sử phát hiện và điều trị bệnh u lympho.

- Các xét nghiệm vi sinh: HBsAg, anti-HBs (Hepatitis B surface antibody), anti-HBc total,
HBeAg (Hepatitis B envelope antigen), anti-HBe (Hepatitis B envelope antibody), định lượng antiHBs và HBV-DNA.

\subsection{Xét nghiêm}

- Xét nghiệm HBsAg: Dựa trên nguyên lý kỹ thuật miễn dịch hóa phát quang, thực hiện trên máy xét nghiệm ARCHITECT Plus.

- Xét nghiệm HBeAg/Anti-HBe, anti-HBs, anti$\mathrm{HBc}$ total: Sử dụng kỹ thuật miễn dịch điện hóa phát quang (Electro chimi luminescence immuno assay - ECLIA) trên máy Cobas 8000 (Roche - Hitachi)

- Xét nghiệm HBV-DNA: Được định lượng bởi kĩ thuật real time - PCR trên máy PCR-Realtime COBAS® TaqMan48 Analyzer, phầm mềm AMPLILINK phiên bản 3.2.0 (Roche - Thụy Sĩ). Ngưỡng phát hiện là $20 \mathrm{IU} / \mathrm{ml}$.

- Xét nghiệm định lượng anti-HBs: Sử dụng kỹ thuật miến dịch điện hóa phát quang trên máy Cobas 6000.

\subsection{Quản lý và phân tích số liệu}

- Số liệu được nhập và xử lý theo chương trình xử lý số liệu SPSS 20.

- Dùng các thuật toán thống kê y học: Tính tỷ lệ \%, giá trị trung bình, độ lệch, trung vị, min, max.

\section{KẾT QUẢ NGHIÊN CỨU}

Trong thời gian từ tháng 8/2020 đến tháng 7/2021, tại trung tâm Huyết học và Truyền máu, Bệnh viện Bạch Mai, chúng tôi ghi nhận được 25 bệnh nhân nhiễm HBV mắc u lympho

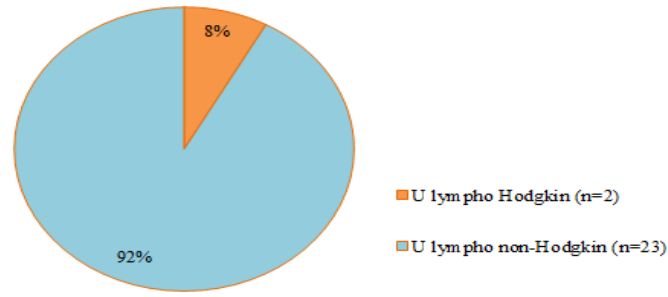

Biểu đồ 1: Phân bố bênh nhân theo bênh máu Trong tổng số 25 bệnh nhân, có 2 bệnh nhân mắc $\mathrm{HL}$, chiếm $8 \%$, còn lại 23 bệnh nhần $(92 \%)$ mắc NHL.

Bảng 1: Đặc điểm chung của đôî tượng nghiên cứu

\begin{tabular}{|c|c|c|c|c|c|c|c|c|}
\hline \multicolumn{3}{|c|}{ Đăc điếm } & $n=25$ & $\%$ & \multicolumn{2}{|l|}{ Đặc điếm } & $n=25$ & $\%$ \\
\hline \multirow{2}{*}{\multicolumn{2}{|c|}{ Giới }} & Nam & 18 & 72 & \multirow{2}{*}{ Tiền sử điều trị NAs } & Có & 1 & 4 \\
\hline & & Nữ & 7 & 28 & & Không & 24 & 96 \\
\hline \multirow{2}{*}{\multicolumn{2}{|c|}{$\begin{array}{c}\text { Tiền sử nhiếm } \\
\text { HBV }\end{array}$}} & Có & 11 & 44 & \multirow{2}{*}{$\begin{array}{c}\text { Tiền sư phát hiện } \\
\text { u lympho }\end{array}$} & Có & 16 & 64 \\
\hline & & Không & 14 & 56 & & Không & 9 & 36 \\
\hline \multirow{2}{*}{ Tuổi } & \multicolumn{2}{|c|}{ Mean \pm SD } & Min & $\max$ & \multirow{2}{*}{$\begin{array}{c}\text { Tiền sử điều trị } \\
\text { u lympho }\end{array}$} & Có & 7 & 28 \\
\hline & \multicolumn{2}{|c|}{$53,1 \pm 14,2$} & 28 & 75 & & Không & 18 & 28 \\
\hline
\end{tabular}

(Mean: Giá trị trung bình, SD: Đô lệch chuấn, Min: giá trị nhỏ nhất, Max: giá trị lớn nhất)

Số lương nam giới là 18 bênh nhân, chiếm $72 \%$, cao hơn so với $28 \%$ ở nữ giới $(p=0,043)$. Có 11 bệnh nhần (44\%) đã phát hiện nhiễm HBV nhưng chỉ có 1 bệnh nhân (4\%) là đã được điêuu trị NAs. Trong số 16 bệnh nhân đã phát hiện u lympho $(64 \%)$ thì chỉ có 7 bệnh nhân $(28 \%)$ là đã từng điêu 
trị ít nhất 1 đợt. Tuổi trung bình của nhóm nghiên cứu là 53,1 $\pm 14,2$ (tuổi) người trẻ nhất 28 tuổi, cao tuổi nhất là 75 tuổi.

Bảng 2: Đặc điểm xét nghiệm vi rút học

\begin{tabular}{|c|c|c|c|c|c|c|}
\hline \multirow{2}{*}{ Xét nghiệm } & \multicolumn{2}{|c|}{ Dương tính } & \multicolumn{2}{|c|}{ Äm tính } & \multicolumn{2}{c|}{ Tống } \\
\cline { 2 - 7 } & $\mathbf{n}$ & $\mathbf{\%}$ & $\mathbf{n}$ & $\mathbf{\%}$ & $\mathbf{n}$ & $\mathbf{\%}$ \\
\hline $\mathrm{HBSAg}(\mathrm{n}=25)$ & 19 & 76 & 6 & 24 & 25 & 100 \\
\hline Anti-HBctotal $(\mathrm{n}=10)$ & 10 & 100 & 0 & 0 & 10 & 100 \\
\hline $\mathrm{HBeAg}(\mathrm{n}=17)$ & 4 & 23,5 & 13 & 76,5 & 17 & 100 \\
\hline Anti-HBe $(\mathrm{n}=17)$ & 6 & 35,3 & 11 & 64,7 & 17 & 100 \\
\hline
\end{tabular}

Tất cả 25 bệnh nhân đều được xét nghiệm $\mathrm{HBsAg}$, với 19 bệnh nhân (76\%) HBsAg dương tính, cao hơn so với 6 bệnh nhân (24\%) HBsAg âm tính và anti-HBc total dương tính $(p=0,015)$. Anti-HBc total được xét nghiệm ở 10 bệnh nhân (40\%) và không ghi nhận giá trị âm tính nào.

Bảng 3: Đặc điểm anti-HBe theo HBeAg

\begin{tabular}{|c|c|c|c|c|c|c|c|}
\hline \multicolumn{2}{|c|}{} & \multicolumn{6}{c|}{ Anti-Hbe (n=17) } \\
\cline { 3 - 8 } & \multicolumn{2}{|c|}{ Dương tính } & \multicolumn{2}{c|}{ Âm tính } & \multicolumn{2}{c|}{ Tổng } \\
\cline { 3 - 8 } & $\mathbf{n}$ & $\mathbf{\%}$ & $\mathbf{n}$ & $\mathbf{\%}$ & $\mathbf{n}$ & $\%$ \\
\hline HbeAg & Dương tính & 0 & 0 & 4 & 100 & 4 & 100 \\
\cline { 2 - 8 }$(n=17)$ & Âm tính & 6 & 46,2 & 7 & 53,8 & 13 & 100 \\
\hline
\end{tabular}

Xét nghiệm $\mathrm{HBeAg}$ và anti-HBe được thực hiện ở 17 bệnh nhân, với tỷ lệ dương tính lần lượt là $23,5 \%$ và $35,3 \%$. Tất cả các bệnh nhân dương tính với $\mathrm{HBeAg}$ đều âm tính với anti-HBe và ngược lại. Tuy nhiên, trong 13 bệnh nhân HBeAg âm tính, anti-HBe dương tính ở 6 bệnh nhân $(46,2 \%)$ và 7 bệnh nhân anti-HBe $(53,8 \%)$ cũng âm tính.

Bảng 4: Tải lượng HBV-DNA

\begin{tabular}{|c|c|c|c|c|c|}
\hline & \multicolumn{2}{|c|}{ Dưới ngưỡng phát hiện } & \multicolumn{2}{c|}{ Trên ngưỡng phát hiện } & Tống \\
\hline HBV-DNA $(\mathrm{n}=20)$ & \multicolumn{2}{|c|}{$3(15 \%)$} & \multicolumn{2}{|c|}{$17(85 \%)$} & $20(100 \%)$ \\
\hline HBV-DNA $(\log \mathrm{IU} / \mathrm{ml}, \mathrm{n}=17)$ & Mean & Median & SD & Min & Max \\
\hline
\end{tabular}

(Median: Trung vị)

Trong 20 bệnh nhân được làm xét nghiệm HBV-DNA đo tải lượng hệ thống tự động, kết quả không phát hiện ở 3 trường hợp (15\%), phát hiện được HBV-DNA ở 17 trường hợp (85\%) (ngưỡng phát hiện $20 \mathrm{IU} / \mathrm{ml}$, tương đương 1,3 $\operatorname{logIU} / \mathrm{ml})$ bất kế tình trạng HBsAg. Giá trị tải lượng HBV-DNA thấp nhất phát hiện được là $1,69 \log \mathrm{IU} / \mathrm{ml}$, giá trị cao nhất là $8,59 \log \mathrm{IU} / \mathrm{ml}$, giá trị trung bình là $4,38 \log \mathrm{IU} / \mathrm{ml}$ và trung vị là 3,87 logIU/ml. Có 3 bệnh nhân có HBV-DNA ở mức lớn hơn $2 \times 10^{7} \mathrm{IU} / \mathrm{ml}(7,3 \log \mathrm{IU} / \mathrm{ml})$.

Anti-HBs được xét nghiệm ở 3 bệnh nhân và có 2 bệnh nhân kết quả dương tính. Trong đó, 1 bệnh nhân được định lượng anti-HBs và kết quả là $40 \mathrm{IU} / \mathrm{ml}$. Bệnh nhân này cũng đồng thời có HBsAg âm tính, anti-HBc total dương tính và HBV-DNA là 7,9 logIU/ml. 1 bệnh nhân có antiHBs và $\mathrm{HBs} A g$ cùng dương tính với HBV-DNA đo được là 1,97 logiU/ml.

\section{BÀN LUẬN}

Viêm gan, suy gan thậm chí tử vong do tái hoạt động của HBV trong và sau quá trình điều trị hóa chất cho bệnh u lympho đã được ghi nhận. Nhiễm HBV đặc biệt ở nhóm HBsAg dương tính, được cho là làm tăng đáng kể nguy cơ mắc u lympho ${ }^{3}$. Do đó, việc sàng lọc đầy đủ, phát hiện những bệnh nhân nhiễm HBV là một khởi đầu quan trọng. Trong thực tiễn lâm sàng, hiện còn ghi nhận được các trường hợp tái hoạt động của HBV liên quan đến điêu trị u lympho, đặc biệt là ở nhóm bênh nhân điều trị hóa chất có kháng thể đơn dòng chống protein CD20 như Rituximab mà chưa được dự phòng NAs trước đó, nghiên cứu này giúp cung cấp cho các nhà lâm sàng về đặc điểm các dấu ấn HBV trong nhóm bệnh nhân nhiễm HBV mắc bệnh u lympho.

Nghiên cứu của chúng tôi tiến hành trên 25 bệnh nhân nhiễm HBV mắc u lympho, với nam giới chiếm tỷ lệ cao hơn và tuổi trung bình là $53,1 \pm 14,2$ (năm) (bảng 1), phù hợp với nghiên cứu của Xiang Zhou và cộng sự trên 40 bệnh nhân u lympho tế bào $B$ lớn lan tỏa khổng đặc hiệu, với giới nam chiếm chiếm $71 \%$ và tuổi trung bình là 61 tuổi ${ }^{2}$.

Tỷ lệ bệnh nhân có HBsAg dương tính của chúng tôi là $76 \%$ (bảng 2), có chênh lệch so với 2 với nghiên cứu của Xiang Zhou là $59 \%$ và $44 \%{ }^{2,4}$. Trong khi đó, nghiên cứu của Jing Meng và cộng sự công bố năm 2019 tiến hành trên 218627 bệnh nhân nhập viện tại bệnh viện đại học Cát Lẩm (không kể tới bệnh lý), Trung Quốc 
từ 2010 - 2014, có 58320 bệnh nhân anti-HBc dương tính, trong số đó $\mathrm{HBsAg}$ dương tính chiếm $27,8 \%$, còn $72,2 \%$ là nhóm $\mathrm{HBsAg}$ âm tính và anti-HBc total dương tính ${ }^{5}$. Nghiên cứu của chúng tôi khác biệt về cỡ mẫu, đối tượng nghiên cứu và đồng thời, dịch tễ học HBV của Việt Nam so với Trung Quốc không hoàn toàn giống nhau, có thể những điều này dẫn tới sự không đồng nhất giữa kết quả của chúng tồi so với các nghiên cứu kể trên. Đặc biệt, nghiên cứu của Zing Meng tiến hành trên nhóm bệnh nhân nhiểm HBV không kể tới các bệnh lý khác cho thấy một kết quả khác biệt rõ rệt. Thêm vào đó, nghiên cứu của Miyoung Kim công bố năm 2019 đã ghi nhận tỷ lệ bệnh nhân có HBsAg dương tính trong nhóm NHL cao hơn so với tỷ lệ này trong nhóm người khỏe mạnh (3,3\% và $0,9 \%)$, đồng thời cũng chỉ ra rằng nhiễm HBV mạn, đặc biệt ở nhóm bệnh nhân có HBsAg dương tính, tăng nguy cơ xuất hiện u lympho ${ }^{3}$. Những kết quả này đặt ra câu hỏi rằng: liệu tỷ lệ bệnh nhân có HBsAg dương tính trong nhóm nhiễm HBV mắc u lympho ở Việt Nam có cao hơn so với tỷ lệ này trong dân số nhiễm HBV cộng đồng hay không?

Trong nhóm bệnh nhân có HBsAg âm tính và anti-HBc total dương tính, chúng tôi ghi nhận được 1 trường hợp phát hiện được anti-HBs với giá trị $40 \mathrm{IU} / \mathrm{ml}$ và HBV-DNA ở mức $7,9 \log \mathrm{IU} / \mathrm{ml}$. Như vậy, kể cả khi HBsAg âm tính, thậm chí xuất hiện anti-HBs, vẫn có trường hợp phát hiện được HBV-DNA của vi rút trong máu. Khái niệm "viêm gan vi rút $B$ thể ẩn" chỉ những bệnh nhẩn nhiễm HBV có HBsAg âm tính, anti-HBc total dương tính, có thể có hoặc không có anti-HBs và HBVDNA phát hiện được trong huyết tương mặc dù ở mức thấp $(<200 \mathrm{IU} / \mathrm{ml})^{6}$. Tuy nhiên, bệnh nhân của chúng tôi có tải lượng HBV-DNA khá cao, đáng tiếc là lại không được làm xét nghiệm HBeAg và anti-HBe, cũng như HBsAg định lượng, do đó liệu đây có phải là một trường hợp viêm gan vi rút $B$ thể ẩn hay kết quả này có liên quan tới độ nhạy của xét nghiệm thì chưa thể khẳng định chắc chắn. Một phẩn tích tổng hợp được xuất bản vào năm 2007 của Zilin Tang và cộng sự chỉ ra nguy cơ tái hoạt động viêm gan vi rút $B$ trong nhóm bệnh nhân có HBsAg âm tính, anti$\mathrm{HBC}$ dương tính không được dự phòng bằng NAs khi điều trị hóa chất có Rituximab cho bệnh u lympho là $9 \% 7$. Đồng thời, các hướng dấn về điều trị dự phòng NAs ở những bệnh nhân sử dụng hóa chất có nguy cơ tái hoạt viêm gan $\mathrm{B}$, đặc biệt là rituximab, đều khuyến cáo xét nghiệm anti-HBc total cho lần sàng lọc đầu tiên trước khi điều trị hóa chất ${ }^{1,8}$. Trong khi đó, trên thực tế, việc tầm soát anti-HBc total còn chưa được tiến hành rộng rãi, đồng thời HBV-DNA đo tải lượng ít khi được thực hiện khi bệnh nhân có HBsAg âm tính, dẫn tới bỏ sót một phần đáng kể bệnh nhân đủ tiêu chuẩn dự phòng NAs.

Sự hiện diện của anti-HBs thể hiện sự đáp ứng miễn dịch đối với HBV. Tuy nhiên, sự có mặt của anti-HBs chưa hẳn đã là một dấu ấn đáng tin cậy cho sự vắng mặt của vi rút trong máu, như 2 trường hợp bệnh nhân trong nghiên cứu của chúng tôi. Các hướng dẫn về điều trị viêm gan vi rút $\mathrm{B}$ đều chưa đề cập tới anti-HBs như là căn cứ để chỉ định sử dụng hay không sử dụng NAs ${ }^{1,8}$. Trong nghiên cứu của chúng tôi, cả 2 bệnh nhân phát hiện được anti-HBs đều được chỉ định NAs trước khi bắt đẩu điều trị hóa chất cho bệnh u lympho.

Chúng tôi ghi nhận HBeAg và anti-HBe dương tính ở $23,5 \%$ và $35,3 \%$ trong nhóm bệnh nhân được làm xét nghiệm (bảng 2). Giá trị HBV-DNA dao động khá lớn từ 1,69-8,59 logIU/ml với mức trung bình là 4,38 logIU/ml (bảng 4). Nhóm bệnh nhân có tải lượng ở mức $\geq 7,3 \log \mathrm{IU} / \mathrm{ml}$ chỉ chiếm $15 \%$. Tỷ lệ HBeAg, anti-HBe dương tính và tỷ lệ $H B V-D N A \geq 7,3 \log I U / m l$ trong nghiên cứu của chúng tôi đều có sự chênh lệch so với $9 \%, 53 \%$ và $6 \%$ tương ứng theo như nghiên cứu của Zhou X2.

Mặc dù còn chưa đạt được sự thống nhất về giá trị tiên lượng của $\mathrm{HBsAg}, \mathrm{HBeAg}$, anti-HBe và HBV-DNA với kết quả điều trị u lympho, nhưng dường như nhiêu hơn các nghiên cứu chuyên sâu trên nhóm bệnh nhân nhiễm HBV mắc u lympho, đặc biệt là $\mathrm{u}$ lympho tế bào $\mathrm{B}$ lớn lan tỏa không đặc hiệu, bước đầu gợi ý cho chúng ta rằng: tình trạng $\mathrm{HBsAg}$, anti-HBs ban đầu không ảnh hưởng đáng kể, trong khi $\mathrm{HBeAg}$ dương tính, HBV-DNA $\geq 2 \times 10^{7} \quad \mathrm{IU} / \mathrm{ml} \quad(7,3$ $\log \mathrm{IU} / \mathrm{ml}$ ) tiên lượng OS và PFS kém hơn so với nhóm còn lại ${ }^{2}$. Tưy nhiên, nghiên cứu của chúng tôi sử dụng phương pháp mô tả cắt ngang, tiến hành trền nhóm bệnh nhân nhiễm HBV mắc u lympho không phân loại với cỡ mẫu là 25, đồng thời, còn một số xét nghiệm về các dấu ấn HBV chưa được thực hiện đầy đủ trên cả nhóm nghiên cứu, do đó không thể kết luận giá trị tiên lượng của các dấu ấn này. Cần có các nghiên cứu với cõ̃ mẫu lớn hơn, theo dõi quá trình điều trị cũng như kết cục điều trị của bệnh nhân để mang lại những kết quả toàn diện hơn.

\section{KẾT LUÂ̂N}

Trong nhóm nghiên cứu, bệnh nhân có HBsAg dương tính chiếm tỷ lệ cao hơn so với nhóm HBsAg âm tính, anti-HBc total dương tính. 
Việc tầm soát ban đầu nên được thực hiện đầy đủ các xét nghiệm theo như hướng dẫn của các hiệp hội về điều trị viêm gan $B$ để tránh bỏ sót nhóm đối tượng cần được dự phòng.

\section{TÀI LIÊUU THAM KHẢO}

1. EASL 2017 Clinical Practice Guidelines on the management of hepatitis $B$ virus infection. J Hepatol. 2017;67(2):370-398. doi:10.1016/ j.jhep.2017.03.021

2. Zhou $\mathbf{X}$, Wuchter $\mathbf{P}$, Egerer $\mathbf{G}$, et al. Role of virological serum markers in patients with both hepatitis $B$ virus infection and diffuse large B-cell lymphoma. Eur J Haematol. 2019;103(4):410-416. doi:10.1111/ejh.13300

3. Kim M, Lee YK, Park B, Oh DJ, Choi HG. Hepatitis virus $B$ and $C$ infections are associated with an increased risk of non-Hodgkin lymphoma: A nested case-control study using a national sample cohort. J Med Virol. 2020;92(8):1214-1220. doi:10.1002/jmv.25653

4. Zhou $X$, Wuchter $P$, Egerer $G$, et al. Serological hepatitis $B$ virus (HBV) activity in patients with HBV infection and B-cell non-Hodgkin's lymphoma. Eur ] Haematol. 2020;104(5):469-475. doi:10.1111/ ejh.13388

5. Meng J, Xu H, Sui $D$, et al. A retrospective serological survey of hepatitis B virus infection in Northeast China. BMC Infect Dis. 2019;19:440. doi:10.1186/s12879-019-4091-3

6. WHO | Guidelines for the prevention, care and treatment of persons with chronic hepatitis $B$ infection. WHO. Accessed May 15, 2020.

7. Tang $Z$, Li $\mathbf{X}$, Wu S, et al. Risk of hepatitis $B$ reactivation in HBsAg-negative/HBcAb-positive patients with undetectable serum HBV DNA after treatment with rituximab for lymphoma: a metaanalysis. Hepatol Int. 2017;11(5):429-433. doi:10.1007/s12072-017-9817-y

8. Bô̂ Y Tế. Hướng dẫn chẩn đoán và điều trị bệnh viểm gan vi rút $\mathrm{B}$. Published online 2019.

\section{ĐĂC ĐIỂM LÂM SÀNG TRIỆU CHỨNG ĂN UỐNG Ở NGƯỜI BÊNH GIAI ĐOẠN TRẦM CẢM ĐIỀU TRI NộI TRÚ TẠI VIỆN SỨC KHỎE TÂM THẦN}

\section{TÓM TẮT}

Trầm cảm là một rối loạn tâm thần phổ biến, mang lại gánh nặng bệnh tật nhiều nhất, gây tổn thất ang đâu về chi phí và thương vong. Trong đó biểu hiện về ăn uống thuộc nhóm triệu chứng sinh học rất thường gặp trong trẩm cảm, ảnh hưởng đến các triệu chứng quan trọng khác như giảm năng lượng hoạt động,

ang sự mệt mỏi và giảm sút trọng lượng cơ thể. Tại Việt Nam cho đến nay đã có nghiên cứu về đắc điểm lâm ang trầm cảm, tuy nhiên việc tiếp cậ̉n triệu chứng ăn uống của trầm cảm còn chưa có nhiều. Do đó, chúng tôi thực hiện nghiên cứu đề tài: "Đặc điểm lâm ang triệu chứng ăn uống ở người bệnh giai đoạn trầm cảm điều trị nội trú tại Viện Sức khỏe Tâm thần". Mục tiêu: "Mô tả đặc điểm lâm ang triệu chứng ăn uống ở người bệnh giai đoạn trầm cảm điểu trị nội trú tại Viện Sức khỏe Tâm thần". Đối tượng và phương pháp nghiên cứu: Nghiên cứu mô tả cắt ngang 68 bệnh nhân giai đoạn trầm cảm điều trị nội trú tại Viện Sức khỏe Tâm thần từ tháng 08/2020 đến tháng 05/2021. Kết quả: Đa phần người bệnh là nữ giới, chiếm 64,7\% tông số người bệnh, độ tuổi trung bình $40.01 \pm 15.79$, nơi sinh sống nhiều hơn ở nông thôn $(55,9 \%)$, trình độ học vấn trung học phổ ang $38.2 \%$. Về đặc điểm triệu chứng ăn uống: thời gian xuất hiện tỷ lệ cao nhẩt là cùng lúc với trầm cảm

\footnotetext{
${ }^{1}$ Đai họ Y Hà Nôi

${ }^{2}$ Viện Sức khoé Tâm thần Quốc gia, Bệnh viện Bạch Mai. Chịu trách nhiệm chính: Nguyễn Thu Hà

Email: hanguyenthu210@gmail.com

Ngày nhận bài: 2.8 .2021

Ngày phản biên khoa học: 30.9.2021

Ngày duyệt bài: 7.10.2021
}

\section{Nguyễn Thu Hà ${ }^{1}$, Trần Nguyễn Ngọc $\mathrm{c}^{1,2}$}

chiếm $63.2 \%$. Giảm cảm giác ngon miệng thường gặp nhất $48.5 \%$, mất cảm giác ngon miệng chiếm $25.0 \%$, ang cảm giác ngon miệng chiếm $11.8 \%$. Về đặc điểm về bữa ăn, ăn không đúng bữa (42.6\%); có $47.1 \%$ người bệnh ăn 3 bữa/ngày, 2 bữa/ngày (35.4\%), 1 bữa/ngày (4.4\%). Người bệnh ăn ít hơn chiếm tỷ lệ nhiêu hơn số người bệnh ăn nhiều hơn $(82.4 \%$ và $13.2 \%)$. Có đến $64,7 \%$ người bệnh có phong cách ăn uống không lành mạnh, trong đó tỷ lệ người bệnh ăn uống thất thường theo cảm xúc chiếm cao nhẩt là $50.0 \%$. Kết luận: Các triệu chứng ăn uống rất thường gặp ở giai đoạn trầm cảm. Vì vậy cân chú ý đến nhóm triệu chứng này để phát hiện và điều trị sớm để cải thiện tình trạng bệnh và nâng cao chất lượng cuộc sống của người bệnh.

Tư khóa: Trâm cảm, cảm giác ngon miệng, ăn uống.

\section{SUMMARY \\ CLINICAL CHARACTERISTICS OF EATING SYMPTOMS IN INPATIENTS WITH DEPRESSIVE EPISODE TREATED AT THE INSTITUTE OF MENTAL HEALTH}

Depression is a common mental disorder, causing the largest disease burden and losing costs and casualties. In particular, the expression of eating and drinking belongs to the group of biological symptoms common in depression, affecting other important symptoms such as psychomotor retardation, increased fatigue, and decreased body weight. In Vietnam, there have been studies on clinical features of depression; however, access to eating symptoms of depression is still not much. Therefore, we conducted a study on the topic: "Clinical characteristics of eating and drinking symptoms in patients with depressive episode inpatient treatment at the Institute of Mental Health". 